\title{
Clinico-Epidemiological Study of Elderly Breast Cancer in a Developing Country: Egypt
}

\author{
Noha Yehia Ibrahim, Soha Talima, Wael Samir Makar \\ Clinical Oncology Department (NEMROCK), Kasr Al-Ainy School of Medicine, Cairo University, Cairo, Egypt \\ Email address: \\ dr.noha11@hotmail.com (N. Y. Ibrahim), soha_talima@hotmail.com (S. Talima),wael_makar@yahoo.com (W. S. Makar) \\ To cite this article: \\ Noha Yehia Ibrahim, Soha Talima, Wael Samir Makar. Clinico-Epidemiological Study of Elderly Breast Cancer in a Developing Country: \\ Egypt. Journal of Cancer Treatment and Research. Vol. 7, No. 1, 2019, pp. 23-27. doi: 10.11648/j.jctr.20190701.14
}

Received: March 11, 2019; Accepted: April 26, 2019; Published: May 30, 2019

\begin{abstract}
Context: The prognosis and treatment outcome in elderly breast cancer is not well known. Aim: To study the prognosis and treatment outcome in elderly breast cancer. Methods and materials: This a retrospective study of breast cancer patients' $\geq 70$ years in the period from January 2005 until December 2010 in Egypt. Kaplan Meir overall survival (OS) analysis and disease-free survival (DFS) were done and they were correlated with different prognostic factors. Results: Among 186 old patients, 139 one were analyzed. The median age was 73.4 years at diagnosis with a mean of 75 . Most patients (70.4\%) were in the range of 70-74 from urban areas (89.2\%) with performance status $1-2(90.6 \%)$ and with $\leq 2$ co-morbidity $(67.6 \%)$. Stage III and IV presented $43.9 \%$. Positive ER and PR was $83.4 \%$ and $75.5 \%$ respectively. Surgery was done in $77.7 \%$ of cases with $62.6 \%$ modified radical mastectomy and $15.1 \%$ conservative lumpectomy and axillary clearance. Treatment included mostly hormonal treatment (79.9\%), radiotherapy (47.5\%) and lastly chemotherapy (18.7\%). The 5-year OS and DFS were 52\% and $53.4 \%$ respectively. The median progression free survival (PFS) in metastatic patients was 4 months. The DFS was significantly affected by performance status (PS), tumor stage, and presence of metastasis. ( $\mathrm{P}$-value $=0.018,<0.001,0.003$ respectively). Conclusion: the 5-year OS was lower than the developed country. The majority of deaths (55.7\%) were not related to breast cancer. Primary tumor stage and metastasis were significant prognostic factor for DFS.
\end{abstract}

Keywords: Breast Cancer, Egypt, Elderly, Epidemiology, Survival

\section{Introduction}

Breast cancer is the most common malignancy in females in Egypt. It accounts for $32 \%$ of cancer in women [1]. It is the leading cause of cancer related mortality, representing $15 \%$ of deaths per year worldwide [2].

A significant increase in breast cancer incidence was evident among women aged 50 years and older, and the highest incidence among women aged 70 years and older [3]

Lately there is increase in the old population above 65 in Egypt that increased from $3.7 \%$ in 2006 to reach $9.3 \%$ in 2014. Life expectancy has also increased to reach 76 years in female and 70 years in males $[4,5]$.

The management of elderly patients is controversial across the studies with trials showing that less aggressive treatment has no impact on recurrence in patients $>70$ as compared to conventional treatment [6]. Where-as other studies highlight the importance of aggressive treatment in improving DFS and OS in the elderly patients [7].
There is limited data in developing countries on elderly breast cancer patients due to poor performance status and limited inclusion of elderly in clinical trials. There is also under treatment of patients as regard surgery, radiotherapy and chemotherapy.

\section{Methods}

All women treated for breast cancer aged 70 and above were identified in the period between January 2005 and December 2010. These included all patients who presented at any stage of the disease and were treated with curative or palliative intent. Patients with missing data were excluded. A total of 186 were collected. Only 139 had full medical data and were included in the analysis after obtaining the institutional research review board.

Disease free survival was defined as the time interval from the date of diagnosis to the date of relapse. Patients who did not relapse were censored at the end of the study period. 
Progression free survival was defined as the time interval from the date of diagnosis to the date of disease progression in patients with stage IV disease. Overall survival was defined as the time interval from the date of diagnosis to the date of death from any cause.

Patients who were alive were censored at the end of the study period. Patients who died from other causes than breast cancer were censored at the time of death. For early stage operable breast cancer, the standard treatment at the time of the study period included modified radical mastectomy or wide local excision and axillary clearance. Chemotherapy was not indicated as adjuvant treatment as a routine practice in this group of patients. However, patients having high risk of recurrence were treated with adjuvant chemotherapy if they have no significant comorbidity and good performance status. Indications for adjuvant radiotherapy included patients who underwent breast conserving surgery (BCS) and high risk post-mastectomy patients with tumor size $5 \mathrm{~cm}$ or more with 4 or more metastatic lymph nodes or positive surgical margins.

Adjuvant hormonal therapy was indicated for patients with ER or PR positive tumors or unknown ER status. Patients with locally advanced disease could undergo neoadjuvant chemotherapy or hormonal therapy followed by surgery. Surgery was not indicated in the presence of extensive local disease or metastatic disease. Palliative chemotherapy, hormone therapy or radiotherapy was given in the metastatic setting.

Statistical analysis was performed using the SPSS version 15.0 software. Survival probabilities was estimated using the Kaplan-Meier method and differences in survival compared using the log-rank test.

\section{Results}

There were $186(4.64 \%)$ old breast cancer patients $\geq 70$ years. This presented $4.64 \%$ of the total 4008 breast cancer cases in the period between January 2005 and December 2010. Only 139 patients had full medical data and were included in the study.

The age ranged between 70 and 86 years with a median of 73.4 years and a mean of 75 . Most of the patients $(70.4 \%)$ were in the range of $70-74$, from urban areas $(89.2 \%)$ with performance status $1-2(90.6 \%)$ and with $\leq 2$ co morbidity (91.4\%). Metastasis was present in 27 patients $(19.4 \%)$. These included bone (75\%), lung (8.3\%) and liver (16.7\%). Patient's characteristics and treatment received are illustrated in table 1 and 2 .

Table 1. Characteristics of Patients and Tumors.

\begin{tabular}{lll}
\hline & $\mathbf{N}=\mathbf{1 3 9}$ & $\mathbf{\%}$ \\
\hline Age Range & $70-86$ & \\
$70-74$ & 98 & 70.5 \\
$75-79$ & 13 & 9.4 \\
80 and above & 28 & 20.1 \\
Residency & & \\
Rural & 15 & 10.8 \\
Urban & 124 & 89.2 \\
\hline
\end{tabular}

\begin{tabular}{|c|c|c|}
\hline & $\mathrm{N}=139$ & $\%$ \\
\hline \multicolumn{3}{|c|}{ ECOG Performance } \\
\hline $0-1$ & 36 & 25.9 \\
\hline 2 & 90 & 64.7 \\
\hline 3 & 13 & 9.4 \\
\hline \multicolumn{3}{|c|}{ No of Co-morbidity } \\
\hline 0 & 53 & 38.2 \\
\hline 1 & 41 & 29.5 \\
\hline 2 & 33 & 23.7 \\
\hline 3 or more & 12 & 8.6 \\
\hline \multicolumn{3}{|c|}{ Primary Tumor Stage } \\
\hline$<5 \mathrm{~cm}$ & 99 & 71.2 \\
\hline$>5 \mathrm{~cm}$ & 40 & 28.8 \\
\hline \multicolumn{3}{|c|}{ Nodal status } \\
\hline Negative & 33 & 23.7 \\
\hline Positive & 106 & 76.3 \\
\hline \multicolumn{3}{|c|}{ Positive nodes } \\
\hline $1-3$ & 28 & 20.1 \\
\hline$>4$ & 57 & 41 \\
\hline Missing & 21 & 15.1 \\
\hline \multicolumn{3}{|c|}{ Presence of Metastasis } \\
\hline No & 112 & 80.6 \\
\hline Yes & 27 & 19.4 \\
\hline \multicolumn{3}{|c|}{ Overall AJCC Stage } \\
\hline I & 14 & 10.1 \\
\hline II & 64 & 46 \\
\hline III & 34 & 24.5 \\
\hline IV & 27 & 19.4 \\
\hline \multicolumn{3}{|c|}{ Histological Type } \\
\hline Ductal & 130 & 93.5 \\
\hline Lobular & 5 & 3.6 \\
\hline Medullary & 4 & 2.9 \\
\hline \multicolumn{3}{|c|}{ Tumor Grade } \\
\hline 1 & 0 & 0 \\
\hline 2 & 135 & 97.1 \\
\hline 3 & 4 & 2.9 \\
\hline \multicolumn{3}{|l|}{ ER Status } \\
\hline Negative & 23 & 16.6 \\
\hline Positive & 116 & 83.4 \\
\hline \multicolumn{3}{|l|}{ PR Status } \\
\hline Negative & 34 & 24.5 \\
\hline Positive & 105 & 75.5 \\
\hline \multicolumn{3}{|c|}{ Her-2 Status } \\
\hline Negative & 111 & 79.9 \\
\hline Positive & 28 & 20.1 \\
\hline
\end{tabular}

Table 2. Treatment Characteristics.

\begin{tabular}{lll}
\hline Therapy & N =139 & Percent\% \\
\hline Surgery & & \\
Biopsy & 31 & 22.3 \\
Lumpectomy \& AC & 21 & 15.1 \\
Mastectomy \& AC & 87 & 62.6 \\
Adjuvant Radiotherapy & & \\
Yes & 73 & 52.5 \\
No & 66 & 47.5 \\
Neoadjuvant/Adjuvant chemotherapy & & \\
Yes & 26 & 18.7 \\
No & 113 & 81.3 \\
Adjuvant Hormonal Therapy & & \\
Yes & 111 & 79.9 \\
No & 28 & 20.1 \\
Treatment Received & & \\
Standard & 104 & 74.8 \\
Non-Standard & 35 & 25.2 \\
Reasons for Non-Standard Treatment & & \\
Total=35 & & \\
Patient refusal & 9 & 25.7 \\
\hline
\end{tabular}




\begin{tabular}{lll}
\hline Therapy & $\mathbf{N}=\mathbf{1 3 9}$ & Percent\% \\
\hline Poor performance status & 15 & 42.9 \\
Co-morbidities & 11 & 31.4 \\
\hline
\end{tabular}

Pathologic examination

All the patients were diagnosed with a clinically palpable mass not based on mammography. The most common histology was Invasive duct carcinoma (IDC) (93.5\%). Duct carcinoma in situ (DCIS) was not found. Invasive lobular carcinoma (ILC) was found in 5 cases $(3.6 \%)$. They were older than 80 years with stage II or III disease and with tumor less than $5 \mathrm{~cm}$ in $70 \%$ of cases. Nodal involvement was high in the majority of cases $(76.3 \%)$ with more than four positive nodes in $41 \%$ of patients. Most of cases were ER positive (83.4\%), PR positive (75.5\%) and HER2 negative (79.9\%)

Surgical characteristics

A total of 31 patients $(22.1 \%)$ underwent biopsy of the disease without excision of the primary tumor nor axillary lymph nodes staging. Most of the patients underwent Modified radical mastectomy (MRM) $62.6 \%$ with only $15.1 \%$ underwent Breast conservative surgery (BCS). All patients who had surgical treatment had axillary lymph node dissection.

Treatment received

Chemotherapy was given in few cases $(18.7 \%)$ as adjuvant or neoadjuvant therapy. Regimens included FAC (10\%), FEC (20\%), CMF (20\%), Paclitaxel (30\%) and capcetabine alone $(10 \%)$ or combined with navelbine $(10 \%)$. As regard radiotherapy, it was given to more than half of the patients with good tolerance

Table 3. Disease free survival in 112 patients.

\begin{tabular}{|c|c|c|c|c|}
\hline Variable & No & Percent \% & 5years DFS (\%) & P-value \\
\hline \multicolumn{5}{|l|}{ Age } \\
\hline $70-74$ & 98 & 70.5 & 75 & \multirow{2}{*}{$<0.001$} \\
\hline $75-79$ & 13 & 9.4 & 57 & \\
\hline 80 and above & 28 & 20 & 0 & \\
\hline \multicolumn{5}{|c|}{ Performance status } \\
\hline 1 & 38 & 34 & 83 & \multirow{3}{*}{0.018} \\
\hline 2 & 65 & 58 & 56.2 & \\
\hline 3 & 9 & 8 & 50 & \\
\hline \multicolumn{5}{|l|}{ Co morbidity } \\
\hline 0 & 43 & 38.4 & 96 & \multirow{4}{*}{0.009} \\
\hline 1 & 60 & 53.6 & 68 & \\
\hline 2 & 9 & 8 & 65 & \\
\hline$\geq 3$ & & & 41 & \\
\hline \multicolumn{5}{|l|}{ Surgery } \\
\hline No & 27 & 24.1 & 72 & \multirow[t]{2}{*}{0.595} \\
\hline Yes & 85 & 75.9 & 45.3 & \\
\hline \multicolumn{5}{|c|}{ Type of surgery } \\
\hline $\mathrm{BCS}$ & 32 & 28.6 & 68 & \multirow[t]{2}{*}{0.774} \\
\hline MRM & 80 & 71.4 & 41 & \\
\hline \multicolumn{5}{|c|}{ Primary tumor stage } \\
\hline I & 14 & 12.5 & 100 & \multirow{3}{*}{$<0.001$} \\
\hline II & 64 & 57.1 & 61 & \\
\hline III & 34 & 30.4 & 46 & \\
\hline \multicolumn{5}{|l|}{ ER status } \\
\hline Negative & 21 & 18.8 & 53 & \multirow{2}{*}{0.192} \\
\hline Positive & 91 & 81.2 & 97 & \\
\hline
\end{tabular}

Disease free survival was done for 112 patients $(80.6 \%)$ Table 3. After a median follow up of 60 months, 18 patients $(16.3 \%)$ relapsed. Bone deposits were the most common site of recurrence making $66.7 \%(12 / 18)$. Other relapse included contralateral breast and brain metastasis equally (16.7\%).

Survival

The 5-years disease free survival (DFS) was $53.4 \%$. There were 61 deaths with a median follow of 45 months. Breast cancer was the main cause of death in 27 cases (44.3\%). The rest of deaths $(34 / 61,55.7 \%)$ were attributed to other causes. These included age in 9 patients, heart failure in another 8 , acute myocardial infarction in 7 patients, cerebrovascular accidents in 6 patients and liver failure in 4 cases. The 5years DFS for stage I, II, III and IV were 100\%, 61\%, 46\% and $36.4 \%$ respectively. (P-value $=<0.001$ ). The five-years overall survival (OS) for stage I, II, III and IV were $75 \%$, $61 \%, 32 \%$ and 0 respectively $(\mathrm{P}-$ value $=0.0001)$. Performance status $(p=0.018)$, primary tumor stage $(p=<0.001)$ and presence of metastases $(\mathrm{p}=0.003)$ were significant prognostic factors for disease free survival. The remaining 27 metastatic patients who were not analyzed for DFS were analyzed separately for progression free survival (PFS). The overall median PFS was 4 months. DFS and OS are illustrated in figures 1 and 2 .

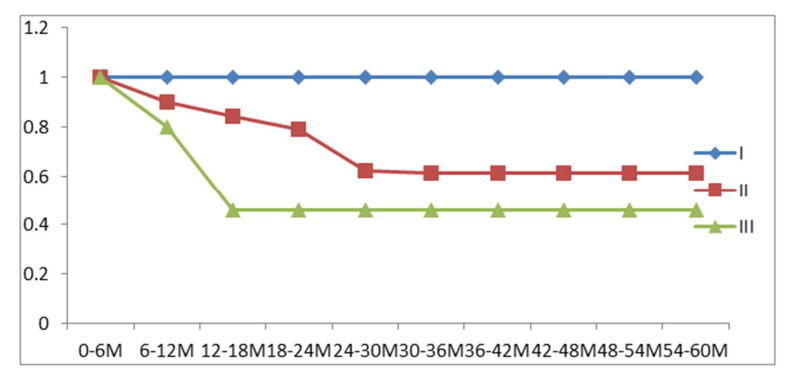

Figure 1. Kaplan-Meier Estimates of disease Free Survival According to overall AJCC Stage. (3 groups: stage I, II and III).

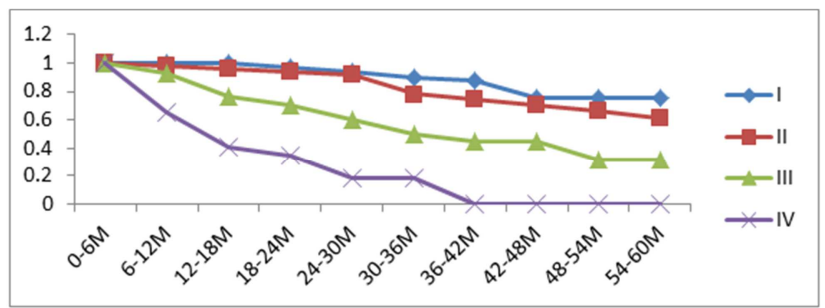

Figure 2. Kaplan-Meier Estimates of overall Survival according to overall AJCC Stage. (4 groups: I, II, III, IV).

\section{Discussion}

The incidence of breast cancer in patients above 70 years was $4.64 \%$ among Egyptian breast cancer with a median age of 73.4 years. The majority were non-metastatic (80.6\%) with performance status $1-2(90.6 \%)$ and $\leq 2$ comorbidity (91.4\%). The 5 years disease free survival was $53.4 \%$ with bone metastases being the most common site of relapse (66.7\%). The overall median progression free survival in the metastatic group was 4 months while the overall survival was 23 months.

The five years overall survival was $52 \%$. This was much lower than western countries when compared to $>82 \%$ in 
England in 70-79 years and falls to $70 \%$ in the age $80-99$ years [8]. However, the overall survival was similar to other developing countries such as Malaysia (51.9\%) [9]. This was attributed to the different patient characteristics in this series. Stage III and IV presented $43.9 \%$ with $41 \%$ having $\geq 4$ lymph nodes with high mean tumor size $(4.9 \mathrm{~cm})$. Also, the urban population presented the majority $(89.2 \%)$. This is associated to obesity in several studies [10] as rural regions are accompanied by more daily physical activity [11].

In a Turkish study conducted by Kartal et al 2013, more than 1000 elderly breast cancer patient above 65 years at diagnosis were investigated. The incidence of breast cancer was $15.5 \%$ in the age $\geq 70$ years. The survival probability at 5 years was $84.0 \%$ for the age $70-74$ years, and $59.6 \%$, for $\geq 75$ years. On multivariate analysis, age, clinical stage, and comorbidity were bad prognostic factors and adversely affected the survival of this elder population of patients [12]. This was in accordance with the cancer survival in England in 2013 done in patients diagnosed between 2007 -2011. This study showed the lowest net five-year survival in elderly patients, age 80-99 years regardless of any other cause of mortality related to this age group [13].

Analysis of 4,453 female breast cancer patients diagnosed in Sweden during the period 1961 and 1991 was done by Brandt et al 2015. The patients were followed up for 10years Breast cancer-specific mortality (BCSM) rate was worse in old age (70-79), however age above 80 years had the worst prognosis and the poorest survival. This was not related to initial stage or the period from diagnosis [14]. This was consistent with the present study, where age affected the disease free survival. $(\mathrm{p}=<0.001)$.

The tumor stage was the most significant evident prognostic factor for DFS which ranged from $100 \%$ for stage I to reach $46 \%$ for stage III $(\mathrm{p}=<0.001)$. Patients with stage II and IV presented $43.9 \%$. This high percent emphasizes the early detection and diagnosis of breast cancer in elderly.

All of our patients presented by palpable mass with no cases diagnosed based on mammography. Patients in this population thought medical care late. Culturally, they believe that they do not have much to live being old and they cannot support any sort of heavy treatment. They are usually not aware of the rising age lately in the population and the recent advances in the treatment of cancer as well as good supportive care provided in most oncology centers. This is in addition to the poor socio-economic state leading to difficulty to reach medical services.

The ECOG performance status (PS) significantly affected the DFS $(p=0.018)$. Five-year DFS was $83 \%, 56.2 \%$ and $50 \%$ for PS 1,2 and 3 respectively. This was in accordance with Phua et al 2010 showing PS as an independent factor for overall survival [9]. In the present study $74.1 \%$ presented with PS $\geq 2$ and this may have attributed to the low overall survival.

The presence of $\geq 3$ comorbidity directly affected the DFS $(p=0.009)$. This is the main cause behind decrease survival in this population due to medical problems not caused by cancer. Elder breast cancer carried a good prognosis if it is not accompanied by any comorbidity. This was in accordance with a study by Hancke $\mathrm{K}$ et al 2010 , that showed an increase of hazard ratio (HR) by 1.3 with comorbid disease independent of age, stage or treatment. This ratio rose to 2.3 in another study by Kartal et al.2013 [14, 11].

As regard tumor grade, most of the patients in this study were grade II $(97.1 \%)$ with only $2.9 \%$ grade III. Grade I was not detected in this study. This high tumor biology may be attributed to the low survival in these females, however it was not significant.

The ER status did not affect the DFS in this series. $(p=$ 0.192). However, the incidence of positive ER status in this population was $83.4 \%$ This was comparable to a study done in Italy revealing a positive ER status in $81 \%, 82 \%, 83 \%$ in patient age $65-74$ years, $75-84$ years and 84 years respectively [15]. In another big study including 813 patients above 70 years, the tumor biology was less aggressive. Hormone positivity had the best prognosis whereas the survival of the basal type and the HER2 overexpressed was poor [16].

In the present study, most of our patients underwent MRM $(62.6 \%)$ with axillary dissection done in all surgical treatment due to lack of expertise in sentinel lymph node dissection at that time.

Non-standard treatment was given to $25 \%(35 / 139)$ of patients. This did not affect overall survival as $31.4 \%$ of these patients had other co-morbidity which affected survival. Only $9 \%$ refused standard treatment and $42.9 \%$ had poor performance status. This was contradictory to a metaanalysis conducted by Cappellani et al 2013 that showed the same treatment outcome in elder patients as youngers ones with standard treatment, however some old women with early stage may receive less therapy [17]. In addition, another study done in Japan comparing breast cancer patients in the $70 \mathrm{~s}$ with those in the $80 \mathrm{~s}$ and above revealed that the standard treatment was the main factor minimizing recurrence and distant metastasis [18]. Another study done in metastatic elderly patients showed that performance status and comorbidity were the main factors leading do under treatment in patients above 75 years [19].

The low life expectancy of this population is a factor contributing to the low survival as $55.7 \%$ of deaths occurred due to other causes than cancer. The life expectancy in Egypt at birth is 70 years, 76 for females and 70years in males [4, 5]. This is much lower than the U. K 81.2, 82.8 for Australia and 83.4 years for Switzerland [20]

The study is limited by the relative small number of patients which were recruited retrospectively. However, it represents the clinic-epidemiological characteristic of an elderly breast cancer population in a developing country.

\section{Conclusion}

We conclude that the 5-year overall survival was $52 \%$. Primary tumor stage $(p=<0.001)$ and metastases $(p=0.003)$ were significant prognostic factors for disease free survival. Future perspective should emphasize on the geriatric 
assessment to determine those patients expected to suffer from toxicity and accordingly will be candidate for less treatment.

There should be campaigns addressed to the elderly for awareness of early diagnosis of breast cancer and how to reach health care. The improvement of treatment outcome should be emphasized and integrated in the social media to encourage old women to search for medical help. Advertisement should address to the old population about the increase life expectancy in the world and how they can be treated easily if they were diagnosed early.

\section{Conflict of Interest}

All the authors do not have any possible conflicts of interest.

\section{Author Contribution}

All authors have read the manuscript. The requirement of authorship has been met. Each author believes that the manuscript represents honest work.

\section{Acknowledgements}

We would like to thank all participants, physicians and nurses in the Oncology Centre in Kasr Al Ainy center of clinical oncology and nuclear medicine. Our appreciation extends to the data entry team that facilitated the extraction of information from the medical files.

\section{References}

[1] Ibrahim AS, Khaled H M, Mikhail N NH, Baraka H, Kamel H. Cancer Incidence in Egypt: Results of the National Population-Based Cancer Registry Program. Journal of Cancer Epidemiology 2014. Article ID 437971, 18 pages. http://dx.doi.org/10.1155/2014/437971.

[2] Bray F, Ferlay J, Soerjomataram I, Siegel R, Torre L et al. Global Cancer Statistics 2018: GLOBOCAN Estimates of Incidence and Mortality Worldwide for 36 Cancers in 185 Countries. Cancer Journal for Clinicians, 2018; VOLUME 68, NUMBER 6,| NOVEMBER/DECEMBER

[3] Hirko KA, Soliman AS, Hablas A, Ibrahim A. Seifeldin IA, Ramadan $\mathrm{M}$ et al., Trends in Breast Cancer Incidence Rates by Age and Stage at Diagnosis in Gharbiah, Egypt, over 10 Years (1999-2008). Journal of Cancer Epidemiology 2013. Article ID 916394, 7 pages.

[4] The Egyptian Central Agency for Public Mobilization and Statistics. People [online],

$<$ http://www.capmas.gov.eg/pages_ar.aspx?pageid=544>; 2012 [accessed 26.09.2012]

[5] http://www.indexmundi.com/egypt/demographics_profile.html , search for The Egyptian Central Agency for Public Mobilization and mobilization

[6] Diab SG, Elledge RM, Clark GM. Tumor characteristics and clinical outcome of elderly women with breast cancer. J Natl Cancer Inst 2000; 92:550-6.
[7] Rocco N, Rispoli C, Pango G, et al. Undertreatment of breast cancer in the elderly. BMC Surg 2013; 13(suppl. 2) S26-248213-S2-S26. Epub 2013 oct 8.)

[8] Office for National Statistics. Cancer survival in England: adults diagnosed in 2009 to 2013, followed up to 2014. Newport: ONS; 2015

[9] Phua CE, Bustam AZ, Cheng-Har Yip, Nor Aishah Taib. Prognostic Factors for Elderly Breast Cancer Patients in University Malaya Medical Centre, Malaysia. Asian Pacific Journal of Cancer Prevention 2010; Vol 11, 1205-1211.

[10] Austin A. M, Hill A. G, and Fawzi W. W. Maternal obesity trends in Egypt 1995-2005. Maternal \& Child Nutrition 2013; Vol. 9, no. 2, pp. 167-179.

[11] Kartal M, Tezcan S and Canda T. Diagnosis, treatment characteristics, and survival of women with breast cancer aged 65 and above: a hospital-based retrospective study. BioMed Central. BMC Women's Health 2013, 13:34

[12] Office for National Statistics. (2013). Statistical Bulletin: Cancer survival in England: Patient diagnosed 2007-2011and followed up to 2012. Newport: ONS; 2013.

[13] Brandt J. Garne JP, Tengrup I and Manje J. Age at diagnosis in relation to survival following breast cancer: a cohort study. World Journal of Surgical Oncology 2015; 13:33.

[14] Hancke K, Denkinger MD, König JKurzeder C, Wöckel A, Herr D, Blettner M, Kreienberg R. Standard treatment of female patients with breast cancer decreases substantially for women aged 70 years and older: a German clinical cohort study. Ann Oncol 2010; 21(Suppl 4):748-753.

[15] Daidone MG, Coradini D, Martelli G, et al. Primary breast cancer in elderly women: biological profile and relation with clinical outcome. Critical Rev Oncol/Haematol, 2003, 45, 13325 .

[16] Syed BM, Green AR, Paish EC, et al. Biology of primary breast cancer in older women treated by surgery: with correlation with long-term clinical outcome and comparison with their younger counterparts. $B r \quad J$ Cancer. 2013; 108(5):1042-51.

[17] Cappellani A, Di Vita M, Zanghì A, Cavallaro A, Piccolo G, Majorana M, Barbera G, Berretta M. Prognostic factors in elderly patients with breast Cancer. From 26th National Congress of the Italian Society of Geriatric Surgery. Naples, Italy. 19-22 June 2013. BMC Surgery 2013, 13(Suppl 2):S2

[18] Takuwa H, Tsuji W, Yotsumoto F. Overall survival of elderly patients with breast cancer is not related to breast-cancer specific survival: A single institution experience in Japan. Breast Dis. 2018 Apr 5. doi: 10.3233/BD-170280.

[19] Park JH, Choi IS, Kim KH, et al. Treatment Patterns and Outcomes in Elderly Patients with Metastatic Breast Cancer: A Multicenter Retrospective Study. J Breast Cancer. 2017; 20(4):368-377.

[20] "World Health Statistics (2016). Monitoring health for the SDGs Annex B: tables of health statistics by country, WHO region and globally". World Health Organization. 2016. Retrieved 27 June 2016. 